\section{A produção do lugar de transmissão da leishmaniose tegumentar: o caso da Localidade Pau da Fome na cidade do Rio de Janeiro, Brasil}

\author{
Production of transmission foci for cutaneous \\ leishmaniasis: the case of Pau da Fome, \\ Rio de Janeiro, Brazil
}

\author{
1 Faculdade de Medicina, \\ Universidade Federal \\ Fluminense, Niterói, Brasil. \\ 2 Escola Nacional de Saúde \\ Pública Sergio Arouca, \\ Fundação Oswaldo Cruz, \\ Rio de Janeiro, Brasil. \\ ${ }^{3}$ Instituto de Comunicação \\ e Informação Científica \\ e Tecnológica em Saúde, \\ Fundação Oswaldo Cruz, \\ Rio de Janeiro, Brasil. \\ Correspondência \\ H. Kawa \\ Faculdade de Medicina, \\ Centro de Ciências Médicas, \\ Universidade Federal \\ Fluminense. \\ Rua Marquês do Paraná \\ 303, 3o andar, Prédio Anexo, \\ Niterói, $R J$ \\ 24030-210, Brasil. \\ hkawa@uol.com.br
}

\begin{abstract}
This study analyzes the characteristics of one of the main foci for cutaneous leishmaniasis transmission in the city of Rio de Janeiro, Brazil, examining its territorial configuration and the relations with spatial organization processes. An analytical model was applied to the process of occupation and organization of urban space on a local scale, considering the new functions acquired by the spatial elements expressed by different work relations, land use, and land value. The study employed geoprocessing techniques and classification of images obtained by remote sensing, localization of households, and cases of cutaneous leishmaniasis, associated with qualitative data on the historical process of land occupation and use. The analysis detected areas with distinct conditions of vulnerability and showed that changes in these conditions allowed production of the epidemic in a given time period and its subsequent reduction. The study contributes to monitoring of the disease at the local level and application of effective measures for cutaneous leishmaniasis surveillance and control.
\end{abstract}

Cutaneous Leishmaniasis; Geography; Infectious Disease Transmission; Social Organization
Hélia Kawa 1

Paulo Chagastelles Sabroza 2 Rosely Magalhães de Oliveira 2 Christovam Barcellos 3

\section{Introdução}

A leishmaniose tegumentar é uma endemia que apresenta elevada freqüência no Brasil, com 22.164 casos novos registrados em 2006, além de continuada expansão territorial e ocorrência de diversos padrões de transmissão em diferentes áreas 1.

Os espaços de produção da leishmaniose tegumentar e seus determinantes têm sido bem identificados no nível regional, possibilitando a caracterização de unidades territoriais de maior relevância epidemiológica, denominadas circuitos espaciais de produção das doenças 2 . Há estudos que mostram como o desenvolvimento dos processos produtivos vem induzindo, em nível regional, o aumento das vulnerabilidades socioambientais e a emergência de novos padrões epidemiológicos dessa endemia ${ }^{3,4}$.

Um dos padrões de leishmaniose tegumentar já bem identificados é aquele presente em áreas de ocupação antiga da Mata Atlântica, ao longo do litoral das regiões Nordeste, Sudeste e Sul do Brasil, onde o vetor é Lutzomyia intermedia e a transmissão ocorre predominantemente no domicílio e no seu entorno 5,6,7,8,9. Embora as características epidemiológicas e paisagísticas desses espaços de transmissão sejam semelhantes, elas constituem áreas onde as formas de ocupação do espaço e de uso do solo implicam processos ecológicos e sociais que resultam em grandes diferenças e instabilidade na incidência da leish- 
maniose tegumentar no nível das localidades que o integram.

Um princípio bem estabelecido, nos estudos geográficos, é que os lugares não são apenas pontos de referência cartográfica, mas unidades espaciais de grande complexidade e dinamismo, cujas singularidades não podem ser compreendidas apenas com base nas análises características de nível regional 10 .

Também é reconhecido que estudos locais impõem a utilização de métodos, modelos e variáveis inerentes a esse nível, sempre buscando identificar mediações com aquelas categorias das regiões que as integram. Desse modo, essas categorias regionais seriam estruturantes, delimitando o conjunto das possibilidades dos processos saúde-doença, enquanto as variáveis locais especificariam aquelas que efetivamente se concretizam em uma situação singular de saúde 11 .

Nos estudos epidemiológicos, deveu-se a Pavlovsky e seus seguidores a consolidação da teoria de focos naturais das doenças transmissíveis, que buscava mostrar a importância dos lugares e de suas paisagens na distribuição geográfica das endemias. Posteriormente, outros autores destacaram a relevância da transformação dos focos produzida pelo trabalho humano, na dinâmica espaço-temporal dessas doenças ${ }^{12}$. Nesse modelo, os focos de doenças são considerados unidades espaciais complexas, e na análise da sua organização precisam ser consideradas tanto sua estrutura ecológica como sua estrutura espacial 13 .

Mais recentemente, o conceito de foco foi revisado e vem sendo utilizado nos estudos das doenças emergentes ao mesmo tempo em que tem havido a incorporação de novas técnicas de geoprocessamento e de classificação de imagens de satélite, possibilitando descrever e analisar as características desses espaços de produção de doenças ${ }^{14}$. A utilização de sistemas de informação geográficos e de técnicas de sensoriamento remoto abriu novas perspectivas e desafios metodológicos nas análises dos processos endêmico-epidêmicos de enfermidades transmitidas por vetores em diferentes escalas geográficas 15 .

Por outro lado, a distribuição geográfica dos casos de uma doença transmissível não reflete diretamente a força de transmissão do agente infeccioso nem o potencial de produção da doença nos locais de ocorrência. Além de fatores como a imunidade da população, a mobilidade das pessoas e a qualidade do diagnóstico e registro dos casos, devem-se levar em conta que estes processos apresentam grandes variações no tempo e tendência à dispersão espacial 16 .

A análise da dimensão temporal dos processos endêmico-epidêmicos precisa levar em conta o tempo dos ciclos de transmissão, próprio dos estudos ecológicos, e o tempo não recorrente dos processos históricos.

No nível das localidades, deve-se considerar ainda que eventos singulares, ambientais, sociais ou mesmo aleatórios, do tempo cotidiano, podem ser de grande relevância para a explicação das diferenças na distribuição das doenças mostrando que, além dos métodos estatísticos, sejam utilizadas técnicas qualitativas de coleta de informações de registros históricos, narrativas e de observações diretas na localidade.

Na cidade do Rio de Janeiro, casos autóctones de leishmaniose tegumentar esporádicos já eram diagnosticados desde o início do século XX. Uma primeira epidemia foi registrada em 1922, na localidade Águas Férreas, no maciço da Tijuca, região central da cidade. Após cinqüenta anos sem registros de novos casos, uma nova epidemia passou a atingir localidades situadas em outra área da cidade, na Zona Oeste, nas encostas e várzeas do maciço da Pedra Branca, no ano de 1973, onde ainda existia importante cobertura florestal, com matas de formação secundária e atividades agrícolas residuais 17 .

Nas décadas seguintes, foram estudados alguns desses locais de transmissão com incidência mais elevada, e discutidas as suas características socioespaciais e seus determinantes históricos. Esses estudos mostraram um conjunto de características ecológicas de uma paisagem típica, identificada pela maioria dos pesquisadores da leishmaniose tegumentar, definindo o padrão de lugar de transmissão nesta região, onde a L. intermedia é transmissora 5,18,19,20. Uma das características mais importantes da leishmaniose tegumentar na cidade do Rio de Janeiro foi a presença de uma região de endemicidade na qual múltiplas localidades apresentaram surtos descontínuos e não sincronizados intercalados com outras, onde ocorrem casos isolados, de incidência ocasional 17 .

O objetivo deste trabalho é analisar as características de um dos lugares de transmissão da leishmaniose tegumentar, de relevância na cidade do Rio de Janeiro, considerando suas configurações territoriais e as relações destas com os processos de organização do espaço. Procurouse identificar as mudanças nas condições de vulnerabilidade à endemia que viabilizaram sua produção, considerando as categorias mediadoras entre as variáveis da localidade da região que a engloba e as transformações relevantes associadas ao aumento do risco de adoecer e posteriormente à sua redução. 


\section{Material e métodos}

Pau da Fome encontra-se na área endêmica de leishmaniose tegumentar do Rio de Janeiro, num vale sedimentar formado pelo Rio Grande, no bairro da Taquara, na Região Administrativa de Jacarepaguá, zona oeste do Município do Rio de Janeiro (22055'47”S, 43²5’57”O) (Figura 1).

Foi feito um estudo comparativo na localidade Pau da Fome considerando dois momentos: o primeiro, utilizando dados provenientes de uma investigação epidemiológica realizada em 198221, relacionado às elevadas incidências observadas a partir do final da década de 1970, e, o segundo, corresponde ao estudo de campo realizado em 2002, considerando a ocorrência da endemia de 1997 a 200022

A delimitação e a divisão da localidade em três subáreas foram as mesmas utilizadas nos dois levantamentos, sendo o critério para a estratificação o modo de ocupação do solo e suas características paisagísticas. Foram coletadas informações de registros históricos junto aos moradores da comunidade e feitas observações diretas na localidade 22 .

Os mapas de domicílios e da população foram construídos com base na recuperação dos croquis de campo feitos no primeiro estudo, e
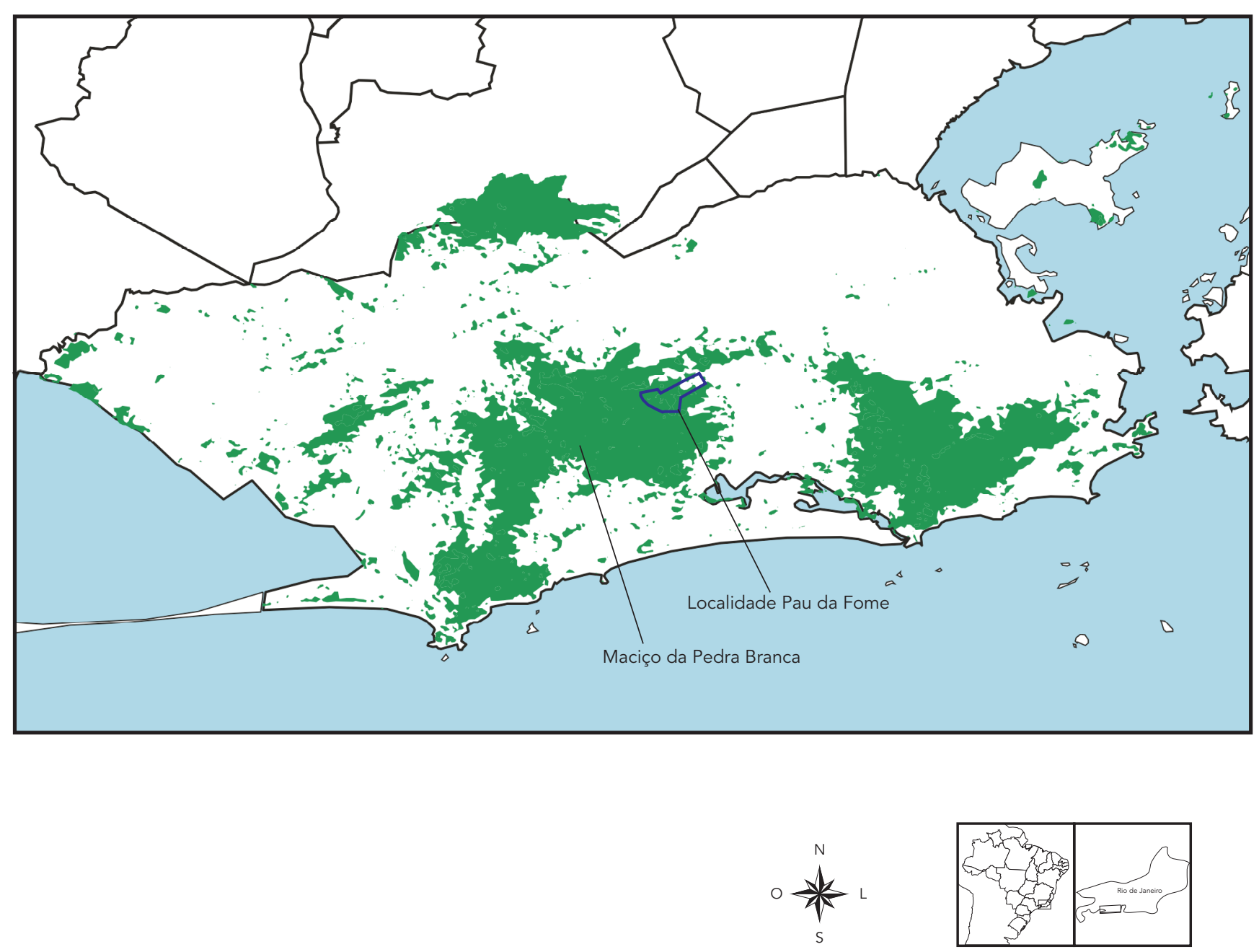
do reconhecimento geográfico realizado pelo Programa de Controle da Leishmaniose Tegumentar na área em 1998. Esse último foi revisado utilizando-se informações das plantas digitais na escala 1:10.000 do Instituto Pereira Passos, da Prefeitura da Cidade do Rio de Janeiro.

Para análise do uso do solo, em relação à cobertura vegetal, foram empregadas imagens do satélite TM Landsat 5 (bandas 3, 4 e 5) de 1984 e TM Landsat 7 (bandas 3, 4 e 5) de 2001, obtidas no Instituto Nacional de Pesquisas Espaciais (INPE) e classificadas pelo método não supervisionado usando-se o classificador denominado Isoseg 23, do programa Spring 24, segundo critérios estabelecidos 25 .

Com base nos mapas temáticos de uso do solo e da distribuição do domicílio e dos casos, foram empregadas técnicas de geoprocessamento por meio do programa Spring, para o cálculo dos parâmetros territoriais utilizados.

As populações de referência do primeiro estudo foram baseadas no levantamento amostral feito na localidade em 1982 18. No segundo estudo 22, utilizaram-se estimativas populacionais considerando o Censo Demográfico de 2000 do Instituto Brasileiro de Geografia e Estatística (IBGE; http://www.ibge.gov.br).

A localização das residências dos casos, no primeiro estudo, foi definida durante o inquérito populacional, sendo georreferenciadas segundo o levantamento obtido nos croquis revisados. No segundo estudo, os endereços foram identificados nas fichas do Sistema de Informação de Agravos de Notificação (SINAN) e em consultas na comunidade. Definiu-se a posição cartográfica com o uso de GPS, utilizando-se os croquis como base cartográfica.

As taxas de detecção calculadas correspondem à proporção de indivíduos residentes na unidade territorial que tiveram diagnóstico registrado de leishmaniose tegumentar no intervalo estudado.

Considerou-se a categoria ecótono, segundo a definição de Dajoz 26, como áreas de transição entre as biocenoses onde a fauna é mais rica e mais abundante do que nas biocenoses adjacentes.

No presente estudo, o ecótono correspondeu a uma faixa total de $60 \mathrm{~m}$, sendo $30 \mathrm{~m}$ para dentro e $30 \mathrm{~m}$ para fora da vegetação densa, a partir da borda entre esta e a vegetação rarefeita, de áreas antrópicas (Figura 2).

Designou-se como microfoco uma pequena unidade territorial de ocorrência de casos, restritos no tempo e articulados em rede na área de transmissão 12 .

A análise da localização dos principais microfocos de leishmaniose tegumentar, caracterizados como superfície de alto e médio riscos, foi feita aplicando-se a técnica de análise espacial de kernel 27, com largura de banda de 30m, considerando os estratos e as áreas definidas como de transição entre a mata e as áreas de ocupação antrópica (ecótonos). Utilizou-se o interpolador IDW (Inverse Distance Weighting) com expoente 2 e grade de $10 \mathrm{~m}$ por $10 \mathrm{~m}$.

\section{Resultados}

A construção social do lugar de transmissão da leishmaniose tegumentar na localidade Pau da Fome

Até por volta da década de 1940, a agricultura foi bastante desenvolvida na localidade, quando os sitiantes plantavam verduras e legumes e os vendiam nas feiras livres. As áreas produtivas, consistindo de propriedades familiares, situavam-se principalmente nas encostas do maciço da Pedra Branca. Os terrenos localizados no vale, ao longo da Estrada do Pau da Fome, haviam sido adquiridos, desde o começo do século, por indivíduos que residiam nas áreas urbanas, fora do Pau da Fome. Poucos foram os que investiram na agricultura. Alguns construíram casas de veraneio de uso esporádico, visando à futura valorização do local 18 .

A partir de 1950, algumas famílias proletárias, vindas de outras localidades dos bairros próximos, se estabeleceram na encosta, ocupando os terrenos abandonados. O acesso à localidade é feito por uma única linha de ônibus que a liga ao centro comercial do bairro, desde meados da década de cinqüenta, cujo ponto final fica próximo à entrada da reserva florestal, nos limites entre o vale e a encosta.

No vale, desde a década de 1960, encontrase o prédio da estação elétrica de Furnas junto à vila residencial dos funcionários da empresa. Ao longo da estrada havia também sítios de veraneio e unidades habitacionais de classe média baixa.

Posteriormente, nos anos setenta, dois vetores de organização do espaço redefiniram o uso do solo na localidade Pau da Fome, expulsando os antigos agricultores das encostas, acima da cota de $100 \mathrm{~m}$ e promovendo a ocupação das áreas mais baixas com habitações irregulares. O primeiro vetor foi a criação de uma nova legislação ambiental 28, impedindo a construção de casas de alvenaria e de lavouras permanentes nas altitudes acima de $100 \mathrm{~m}$. O segundo vetor foi o processo de integração da região de Jacarepaguá, seus bairros e localidades à área urbana da cidade, pela consolidação dos eixos viários e da implantação do pólo industrial de Jacarepaguá. 


\section{Figura 2}

Superfície de risco e casos de leishmaniose tegumentar em ecótonos em imagens obtidas em 1984 e 2001, na Localidade Pau da Fome, Rio de Janeiro, Brasil.
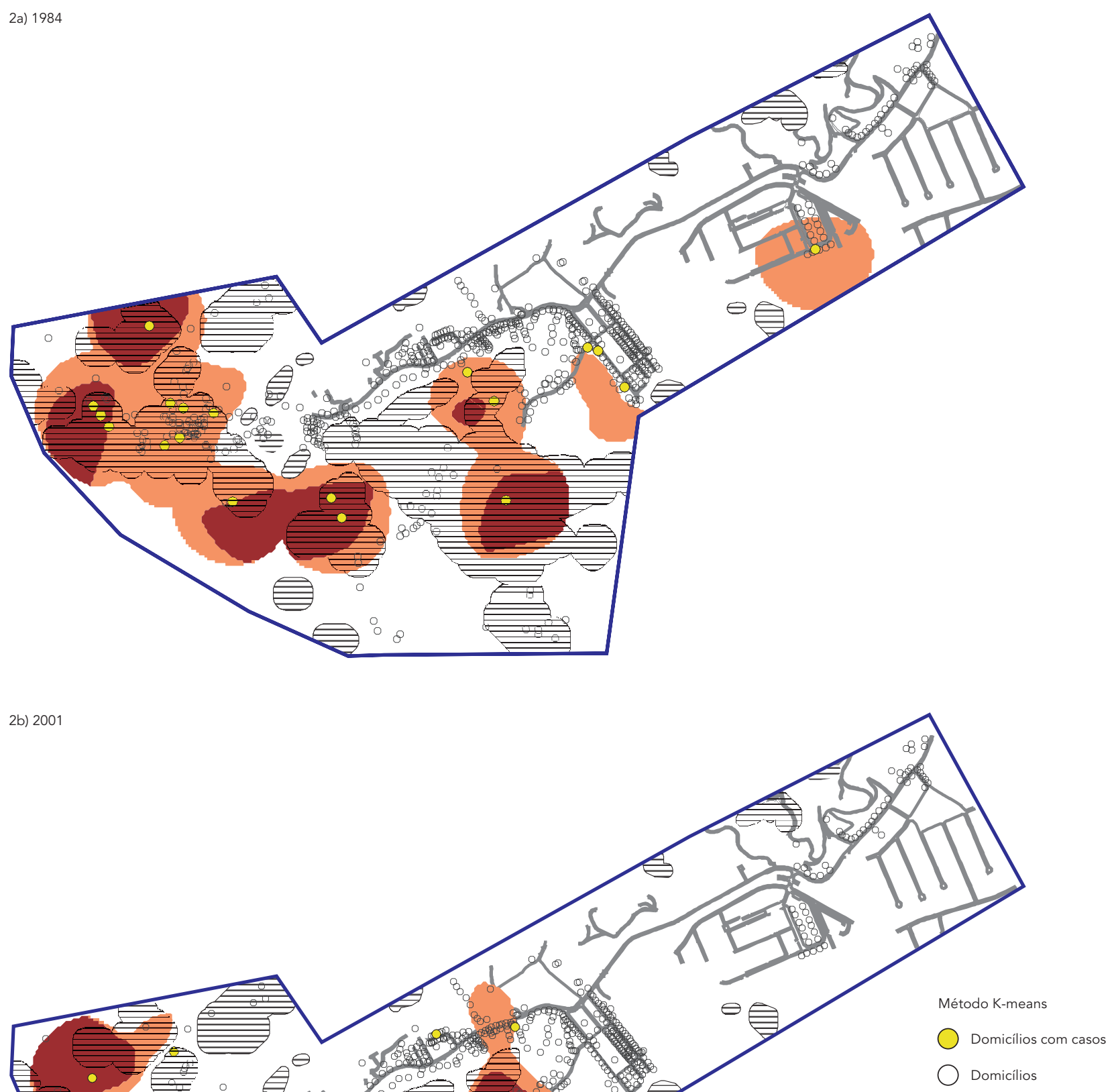

$\bar{\equiv}$ Ecótonos acima da cota $100 \mathrm{~m}$

Superfície de risco



Alto

$\square$ Médio

Ruas e caminhos

$\square$ Limite da área de estudo

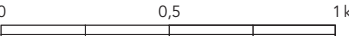


Com isso, houve grande valorização da terra, deslocando os moradores tradicionais e, ao mesmo tempo, atraindo indivíduos na expectativa de emprego nas novas indústrias. Nesse período as propriedades tiveram valorização acentuada, de $150 \%$ a $650 \% 29$.

Na década de 1980, já não havia produção agrícola relevante em Pau da Fome, restando algumas plantações de banana em terrenos da encosta e pequenas hortas, e criação de animais para o autoconsumo, nas áreas mais baixas. Nesse período foi demarcado o Parque Estadual da Pedra Branca, deslocando a população residente, de baixa renda, para os limites externos da área de proteção. Nas áreas de encosta, com o ambiente mais degradado, ainda podiam ser encontrados sítios com criação de gado, assentamentos precários e irregulares.

A partir de 1990, a cobertura vegetal se amplia, as áreas degradadas foram recuperadas e o Parque revitalizado, culminando, no ano 2000, com a construção do portal de acesso, a restauração da antiga sede e a adoção de medidas mais restritivas à entrada na área de preservação (Figura 3). Na região mais alta do vale, nos limites do Parque, cresce o número de habitações precárias e irregulares em decorrência do incremento populacional (Tabela 1).

Nas áreas planas, além da unidade de Furnas e das habitações tradicionais, encontram-se sítios recreativos, de ecoturismo, clubes e, mais recentemente, condomínios de classe média alta.

Uma das características mais importantes do processo de organização do espaço é que ele resultou em distintos modos de uso do solo. No período entre 1985 e 2005, essa diversidade ficou bem marcada, sendo possível identificar três subáreas, de acordo com suas características socioambientais, definidas segundo o modo de ocupação e uso do solo (Tabela 2):

- Subárea I: localizada na encosta, na extremidade superior do vale, com predominância de cobertura vegetal densa, consistindo de Mata Atlântica e bananais, e ocupada por parte de área de preservação e por comunidades residindo em habitações irregulares, no entorno do Parque; comparando os dois anos, 1984 e 2001, destacase a proporção da vegetação rarefeita e o aumento da vegetação densa, além da recomposição da cobertura vegetal;

- Subárea II: localizada também na encosta, em uma vertente do vale, apresenta, em 1985, um porcentual maior de área desmatada. Com a consolidação do Parque, observou-se aumento da cobertura vegetal densa e, principalmente, na sua porção inferior, próxima ao ponto de ônibus e nos limites do vale, um importante incremento da área edificada;
- Subárea III: situada no vale, com cobertura vegetal constituída por árvores frutíferas e ornamentais; esta subárea é a mais consolidada em relação à ocupação antrópica, com grande aumento da área edificada e redução da vegetação rarefeita, por incorporação dos terrenos baldios.

\section{A leishmaniose tegumentar na Localidade Pau da Fome}

Em 1973/1974, quando ocorreu uma epidemia com o registro de 162 casos de leishmaniose tegumentar na região de Jacarepaguá, atingindo diversas localidades situadas nas encostas e várzeas do maciço da Pedra Branca, registrou-se apenas um caso de leishmaniose tegumentar na Localidade Pau da Fome 5 . Nos anos seguintes, a doença se manifestou esporadicamente até 1979, quando houve um surto com 21 casos (Figura 4). Um inquérito imunológico realizado naquele período mostrou valores distintos de positividade à intradermoreação de Montenegro entre os moradores das subáreas: a mais próxima da reserva florestal, a subárea I, apresentou a prevalência mais alta (32,7\%) e, nas subáreas II e III, os valores foram respectivamente de $22,7 \%$ e $11 \% 21$.

Nos três anos seguintes, o número de doentes se manteve elevado. Em 1983, depois que a Superintendência de Campanhas de Saúde Pública (SUCAM) procedeu a dedetização dos domicílios e seus anexos 18, os casos novos diminuíram muito (Figura 4). Posteriormente, o número de casos passou a crescer lentamente atingindo um novo pico em 1987, e outro somente dez anos depois, em 1997. A partir de 2000, quando ocorreram nove doentes, o número de casos diminuiu e não houve registros de leishmaniose tegumentar em 2003 e 2004 na localidade (Figura 4).

Pode-se observar que a freqüência de casos no primeiro levantamento (1984) foi muito mais elevada, havendo uma acentuada diferença entre as subáreas nos dois períodos de estudo (Tabela 1; Figura 3). Chama atenção a subárea I, situada dentro dos limites da reserva e menos integrada ao espaço urbano, pois foi a única que manteve taxas de incidência semelhantes nos dois períodos. A subárea II, considerada intermediária do ponto de vista da integração urbana, registrou, no primeiro estudo, 40,8 casos de leishmaniose tegumentar por mil habitantes, bem maior do que o índice visto no Pau da Fome (17,2 por mil habitantes). Já no segundo período, em 2002, a subárea I passa a liderar a freqüência da doença entre as demais subáreas, sendo superior, inclusive, ao índice observado no conjunto da localidade, enquanto a subárea II apresenta grande redução da taxa, registrando 3,8 casos por mil habitantes. A subárea III, a mais consolidada 
Figura 3

Cobertura vegetal, residências e casos de leishmaniose tegumentar, em imagens obtidas em 1984 e 2001, na Localidade Pau da Fome, Rio de Janeiro, Brasil.

3a) 1984

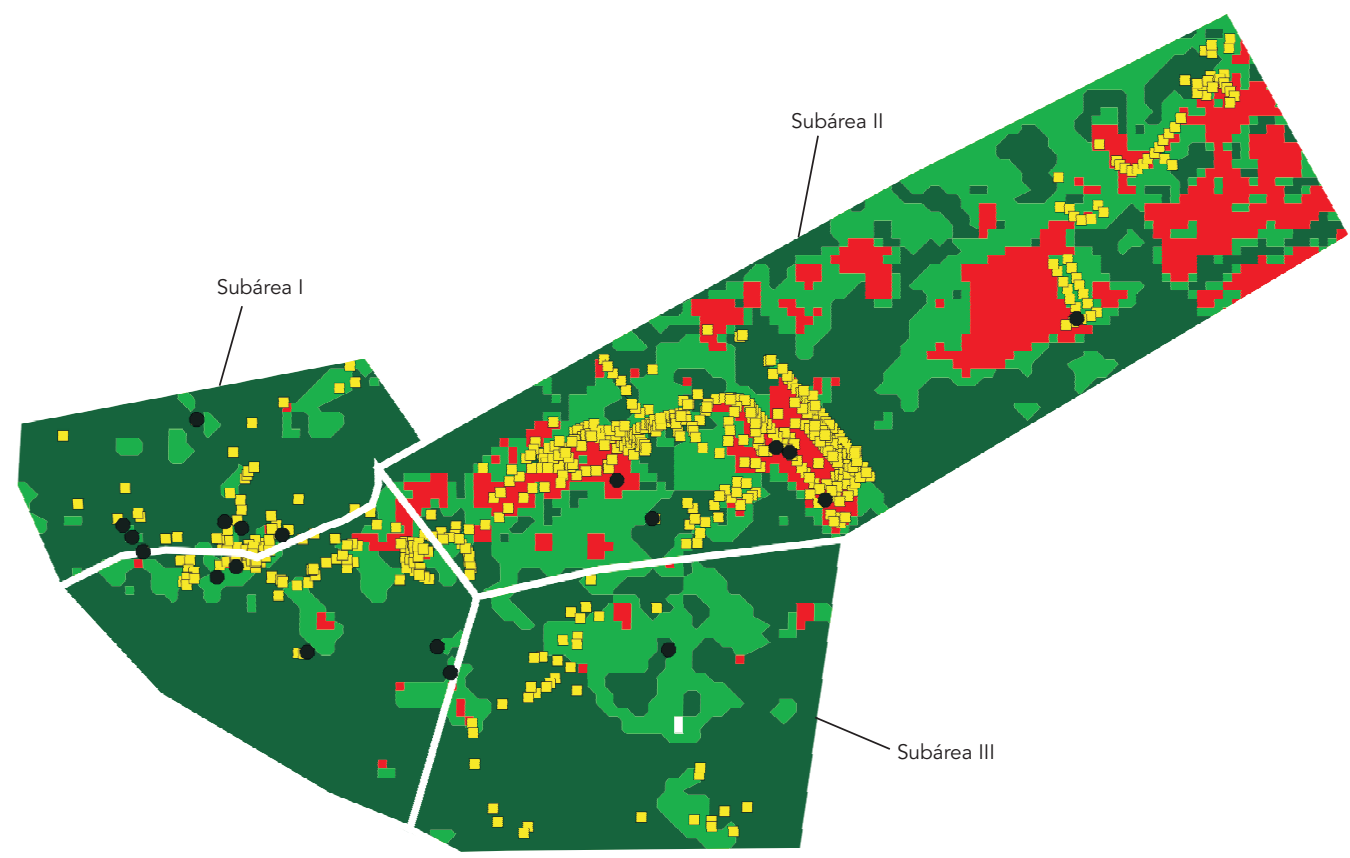

3b) 2001




Características sociodemográficas e epidemiológicas de leishmaniose tegumentar por unidade territorial em dois períodos, 1984 e 2002. Localidade Pau da Fome, Rio de Janeiro, Brasil.

\begin{tabular}{|c|c|c|c|c|}
\hline \multirow[t]{2}{*}{ Características das subáreas } & \multicolumn{3}{|c|}{ Subáreas } & \multirow[t]{2}{*}{ Pau da Fome } \\
\hline & 1 & II & III & \\
\hline Extensão (hectares) & 49,5 & 153,0 & 200,3 & 402,8 \\
\hline \multicolumn{5}{|l|}{ População } \\
\hline Primeiro estudo & 128 & 392 & 542 & 1.062 \\
\hline Segundo estudo & 200 & 466 & 1.443 & 2.109 \\
\hline \multicolumn{5}{|l|}{ Densidade populacional } \\
\hline Primeiro estudo & 2,6 & 2,6 & 5,2 & 2,6 \\
\hline Segundo estudo & 4,0 & 3,0 & 7,2 & 5,2 \\
\hline Incremento populacional & 2,5 & 1,0 & 7,0 & 3,9 \\
\hline \multicolumn{5}{|l|}{ Número de casos } \\
\hline Primeiro estudo & 6 & 64 & 22 & 73 \\
\hline Segundo estudo & 10 & 7 & 7 & 25 \\
\hline \multicolumn{5}{|c|}{ Incidência anual média (por 1.000 habitantes) } \\
\hline Primeiro estudo & 11,7 & 40,8 & 10,1 & 17,2 \\
\hline Segundo estudo & 12,5 & 3.8 & 1,2 & 3,0 \\
\hline
\end{tabular}

Tabela 2

Características sociodemográficas e epidemiológicas de leishmaniose tegumentar por unidade territorial em dois períodos, 1984 e 2002. Localidade Pau da Fome, Rio de Janeiro, Brasil.

\begin{tabular}{|c|c|c|c|c|c|c|c|c|c|}
\hline \multirow{3}{*}{$\begin{array}{l}\text { Unidade } \\
\text { territorial }\end{array}$} & \multicolumn{3}{|c|}{$1984(\%)$} & \multicolumn{3}{|c|}{$2001(\%)$} & \multicolumn{3}{|c|}{ Razão (2001/1984) } \\
\hline & \multicolumn{2}{|c|}{ Vegetação } & \multirow{2}{*}{$\begin{array}{c}\text { Área } \\
\text { edificada }\end{array}$} & \multicolumn{2}{|c|}{ Vegetação } & \multirow{2}{*}{$\begin{array}{c}\text { Área } \\
\text { edificada }\end{array}$} & \multicolumn{2}{|c|}{ Vegetação } & \multirow{2}{*}{$\begin{array}{c}\text { Área } \\
\text { edificada }\end{array}$} \\
\hline & Rarefeita & Densa & & Rarefeita & Densa & & Rarefeita & Densa & \\
\hline Pau da Fome & 41,6 & 52,9 & 5,5 & 27,8 & 59,1 & 13,0 & 0,67 & 1,12 & 2,37 \\
\hline Subárea I & 21,6 & 77,8 & 0,5 & 11,7 & 88,0 & 0,3 & 0,54 & 1,13 & 0,52 \\
\hline Subárea II & 27,9 & 71,8 & 0,2 & 20,2 & 78,0 & 1,7 & 0,72 & 1,09 & 6,84 \\
\hline Subárea III & 57,0 & 32,2 & 10,7 & 37,5 & 37,6 & 24,8 & 0,66 & 1,17 & 2,32 \\
\hline
\end{tabular}

do ponto de vista urbano, manteve-se como a de menor transmissão em Pau da Fome nos dois períodos analisados, com importante queda na incidência, de 10,1 para 1,2 por mil habitantes.

Constatou-se que ocorreram importantes reduções das taxas de detecção da doença nas subáreas I e II, apesar do aumento da proporção da vegetação densa (Tabela 2 ).

\section{A leishmaniose tegumentar em áreas de transição ecológica na Localidade Pau da Fome}

A Tabela 3 apresenta as características epidemiológicas da leishmaniose tegumentar consideran- do a posição dos domicílios em relação aos ecótonos e à altitude. Pode-se observar que, nos dois levantamentos realizados, o número de casos e as taxas de detecção foram muito mais elevados no interior dos ecótonos, destacando-se, principalmente, as áreas situadas nas cotas acima de $100 \mathrm{~m}$ de altitude, onde os índices atingiram valores muito mais expressivos que os observados fora das áreas de transição.

Uma das características mais marcantes do espaço socialmente organizado da localidade estudada é a sua configuração em áreas justapostas, com cobertura vegetal preservada e conglomerados de habitações humanas contíguas, resultando numa grande extensão de áreas de 


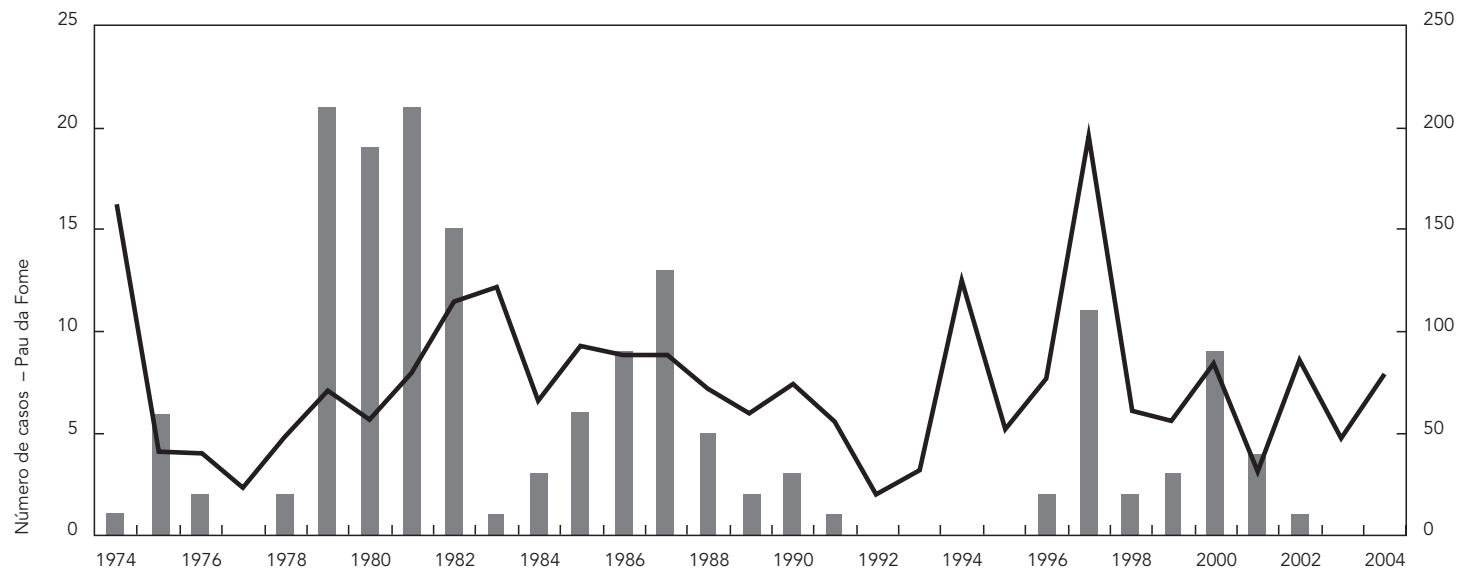

Fonte: Secretaria Municipal de Saúde do Rio de Janeiro.

Tabela 3

Localidade Pau da Fome, Rio de Janeiro, Brasil: características epidemiológicas de leishmaniose tegumentar em ecótonos em dois períodos, por localização dos domicílios.

\begin{tabular}{|c|c|c|c|c|c|c|}
\hline \multirow[t]{3}{*}{ Atributos } & \multicolumn{6}{|c|}{ Posição dos domicílios } \\
\hline & \multicolumn{3}{|c|}{ Dentro dos ecótonos } & \multicolumn{3}{|c|}{ Fora dos ecótonos } \\
\hline & $\leq 100 \mathrm{~m}$ & $>100 m$ & Total & $\leq 100 \mathrm{~m}$ & $>100 \mathrm{~m}$ & Total \\
\hline \multicolumn{7}{|l|}{ População } \\
\hline Primeiro estudo & 422 & 86 & 508 & 213 & 341 & 554 \\
\hline Segundo estudo & 855 & 340 & 1.195 & 703 & 211 & 914 \\
\hline \multicolumn{7}{|l|}{ Número de casos } \\
\hline Primeiro estudo & 10 & 23 & 33 & 3 & 17 & 20 \\
\hline Segundo estudo & - & 17 & 17 & 6 & 1 & 7 \\
\hline \multicolumn{7}{|c|}{ Detecção (por 1.000 habitantes) } \\
\hline Primeiro estudo & 23,7 & 267,4 & 65,0 & 14,1 & 49,9 & 36,1 \\
\hline Segundo estudo & - & 49,9 & 14,2 & 8,5 & 4,7 & 7,7 \\
\hline
\end{tabular}

contato entre as áreas edificadas e as cobertas por vegetação, tanto densa, como rarefeita.

No Pau da Fome, essas áreas ocupavam 218,5 hectares em 1984 e 189,3 hectares em 2001, correspondendo, respectivamente, a $54,1 \%$ e $46 \%$ do total. Acima de $100 \mathrm{~m}$ de altitude as áreas de transição preencheram $44,4 \%$ (93ha) no primeiro estudo e 37,3\% (78,3ha) no segundo. Já abaixo desse limite, os ecótonos cobriam a maior parte da área, tanto em 1984 (64,6\% e 125,5ha) quanto em 2001 (57,1\% e 111ha).
Na Figura 2, verifica-se a distribuição dos ecótonos acima da cota de 100m e a localização dos microfocos de leishmaniose tegumentar, denominados como superfícies de risco alto e médio, para os dois períodos estudados.

Observou-se que, com raras exceções, os domicílios com doentes estavam concentrados nos ecótonos. Verificou-se ainda que alguns focos mantiveram-se nos dois estudos, principalmente nas áreas próximas da reserva florestal (subárea I), enquanto que dois focos de grande 
importância no primeiro estudo, na subárea II, se tornaram inativos e foram substituídos por focos situados mais próximo da estrada.

\section{Discussão}

Neste estudo, empregando-se técnicas cartográficas e de sensoriamento remoto, combinadas à observação direta na localidade, foram identificadas áreas de transição (ecótonos) e as suas principais características, tais como a proporção e o tipo de cobertura vegetal; a distância entre as residências, a mata e a altitude; além de permitir a comparação destas e de outras variáveis em dois períodos.

Os resultados mostram que, no Pau da Fome, no intervalo analisado, de 20 anos, a transmissão da leishmaniose tegumentar permaneceu em atividade com a ocorrência de casos esporádicos e de dois surtos.

Durante os surtos, observou-se a formação de microfocos circunscritos e transitórios, porém situados em áreas distintas na localidade, tanto em 1984 como em 2002.

Nos dois períodos os casos de leishmaniose tegumentar se concentraram nos ecótonos situados acima da cota de 100m, mostrando, portanto, a importância da área de transição entre a vegetação densa, de mata nativa preservada e as áreas de ocupação antrópica pouco consolidadas.

Desse modo, o ecótono não pode ser considerado uma totalidade independente, um fator de risco isolado, pois na medida em que a floresta se consolida, sua superfície passa, inclusive, a ser fator de proteção como ocorreu em outra área da cidade do Rio de Janeiro, onde houve o primeiro surto epidêmico de leishmaniose tegumentar no início do século XX e, até o momento, não foram registrados doentes na área 30 . O que reitera a importância desse tipo de ecótono para a transmissão da leishmaniose tegumentar quando o vetor é a L. intermedia, como mostraram estudos anteriores 31 .

A mudança da localização dos microfocos de maior incidência decorreu principalmente do deslocamento dos grupos populacionais de risco de uma área de ocupação tradicional, na encosta, onde persistem atividades agrícolas, para outra, próxima do vale e do terminal de ônibus, e utilizada por moradias de trabalhadores urbanos, nos limites do Parque Estadual da Pedra Branca. O que mostra a importância dos vetores de organização do espaço regional, como a consolidação do Parque e a integração da região de Jacarepaguá na área urbana da cidade, na produção do espaço local e de situações particulares de risco. Esses processos de ordem mais geral, relaciona- dos à organização do espaço social em determinado período, criam condições particulares de vulnerabilidade socioambiental que se traduzem pela emergência e pelo recrudescimento de diferentes problemas de saúde, constituindo-se em um cronótono, uma janela de tempo, como proposto por Bradley 32 .

É na localidade que se materializam os processos socioambientais que finalmente resultam na ocorrência da doença. As localidades são estruturas únicas que apresentam especificidades decorrentes de uma história singular, expressando, em cada momento, possibilidades distintas que podem ou não viabilizar a transmissão da doença 33,34. Contudo, os estudos locais apresentam um conjunto de questões a serem consideradas. Os resultados obtidos refletem apenas uma parte do problema, pois o conjunto de notificações da enfermidade representa, além de sua incidência, a cobertura do serviço de saúde, a capacidade de diagnosticar a doença e a qualidade do sistema de informação da rede de serviços de saúde. Essas características tornam-se mais importantes numa enfermidade como a leishmaniose tegumentar, cuja lesão, na maioria das vezes, é pequena e indolor, pode cicatrizar espontaneamente, e atinge geralmente indivíduos excluídos dos principais circuitos da economia, que não tiveram possibilidade de transformar a doença em um problema de saúde 22 .

Outra dificuldade encontrada refere-se à base populacional disponível. Embora seja possível obter informações sobre a população residente na escala de setor censitário, sua aplicação no estudo da localidade é restrita, pois os setores do censo de 1991 e 2000 apresentam áreas distintas cujas unidades não podem ser superpostas, reduzindo as possibilidades de seu uso nos estudos epidemiológicos. Deve ser considerado, ainda, que a descontinuidade verificada nos registros de casos e atribuída, em grande parte, às mudanças no fluxo da informação, decorrentes da descentralização do controle de endemias, torna extremamente necessária e urgente a consolidação deste processo, pois, para qualquer análise epidemiológica é fundamental a existência de bases de dados sistemáticas e permanentes.

Contudo, os lugares de transmissão de uma antropozoonose não podem ser definidos apenas pelo número de casos, pois a incidência de uma doença como a leishmaniose tegumentar depende também de um conjunto de dados circunstanciais relacionados a fatores climáticos e ecológicos que influenciam diretamente a dinâmica da população de vetores e reservatórios. Desse modo, a estratificação de cada uma das localidades definida com base nos critérios propostos em levantamentos anteriores, não po- 
deria mostrar equivalência entre os estratos na medida em que, cada um deles corresponde a condições singulares do processo de organização dos lugares.

Da mesma forma, é inerente ao estudo local a instabilidade encontrada nos coeficientes em função do pequeno número de habitantes e do número restrito de casos registrados. Esse grau de incerteza observado na investigação do lugar e nos modelos epidemiológicos, que articulam determinantes biológicos e sociais, é compensado pela riqueza encontrada em abordagens multidisciplinares dos diferentes processos de produção de doenças, e pelas possibilidades de contribuir na formulação de propostas adequadas de intervenção ao controle dessas enfermidades.

\section{Resumo}

Este trabalho analisa as características de um dos lugares de transmissão de maior relevância da leishmaniose tegumentar na cidade do Rio de Janeiro, Brasil, considerando sua configuração territorial e as relações desta com processos de organização do espaço. Utilizou-se o modelo de análise do processo de ocupação e organização do espaço urbano, em escala local, considerando-se as novas funções adquiridas pelos elementos espaciais expressos por diferentes relações de trabalho, uso do solo e valor da terra. Empregaramse técnicas de geoprocessamento e de classificação de imagens obtidas por sensoriamento remoto, localização de domicílios e casos de leishmaniose tegumentar,
Apesar de todas as limitações observadas e da complexidade do estudo local, os dados se mostraram muito úteis quando analisados a partir do modelo, possibilitando identificar os espaços potenciais de transmissão, onde um conjunto de características ambientais, sociais e comportamentais permitiu ou inviabilizou a manutenção da endemia na localidade. Em outras palavras, as condições de vulnerabilidade à endemia foram identificadas, apontando um conjunto de possibilidades de ocorrência da enfermidade que pode contribuir para a construção de um sistema de monitoramento e de vigilância epidemiológica e ambiental, voltado para orientar as ações de controle da leishmaniose tegumentar nos lugares de transmissão. associados a dados qualitativos sobre o processo histórico de ocupação e uso do solo. A análise mostrou áreas com distintas condições de vulnerabilidade, e que mudanças destas condições viabilizaram a produção da epidemia em um determinado período e sua posterior redução. O estudo contribui para o monitoramento da enfermidade em nível local e para a aplicação de medidas eficazes para as ações de vigilância e controle da leishmaniose tegumentar.

Leishmaniose Cutânea; Geografia; Transmissão de Doença Infecciosa; Organização Social 


\section{Colaboradores}

H. Kawa participou na definição do desenho metodológico, na coleta, análise e processamento dos dados, elaboração do artigo e sua redação final. P. C. Sabroza participou na definição do desenho metodológico, na coleta, análise e processamento dos dados, elaboração do artigo e sua redação final. R. M. Oliveira participou na discussão, revisão dos resultados e revisão da redação final. C. Barcellos participou na discussão, revisão dos resultados e revisão da redação final.

\section{Referências}

1. Departamento de Vigilância Epidemiológica, Secretaria de Vigilância em Saúde, Ministério da Saúde. Manual de vigilância da leishmaniose tegumentar americana. Brasília: Ministério da Saúde; 2007.

2. Ministério da Saúde. Vigilância e monitoramento da leishmaniose tegumentar americana em unidades territoriais - Brasil, 1994-2001. Boletim Eletrônico Epidemiológico 2002; 2(5).

3. Marzochi MCA, Marzochi KBF. Tegumentary and visceral leishmaniases in Brazil: emerging anthropozoonosis and possibilities for their control. Cad Saúde Pública 1994; 10 Suppl 2:359-75.

4. Gontijo B, Carvalho MLR. Leishmaniose tegumentar americana. Rev Soc Bras Med Trop 2003; 36: 71-80.

5. Sabroza PC. O domicílio como fator de risco na leishmaniose tegumentar americana: estudo epidemiológico em Jacarepaguá, Município do Rio de Janeiro [Dissertação de Mestrado]. Rio de Janeiro: Escola Nacional de Saúde Pública, Fundação Oswaldo Cruz; 1981.

6. Gomes AC, Neves VLFC. Estratégia e perspectivas de controle da leishmaniose tegumentar no Estado de São Paulo. Rev Soc Bras Med Trop 1998; 31:553-8.

7. Silva LMR, Cunha PR. A urbanização da leishmaniose tegumentar americana no Município de Campinas - São Paulo (SP) e região: magnitude do problema e desafios. An Bras Dermatol 2007; 82:515-9.
8. Cunha JCL, Lima JWO, Pompeu MML. Transmissão domiciliar de leishmaniose tegumentar e associação entre leishmaniose humana e canina, durante uma epidemia na Serra de Baturité, no Estado do Ceará, Brasil. Rev Bras Epidemiol 2006; 9:425-35.

9. Martins LM, Rebêlo JMM, Santos MCFV, Costa JML, Silva AR, Ferreira LA. Ecoepidemiologia da leishmaniose tegumentar no Município de Buriticupu, Amazônia do Maranhão, Brasil, 1996 a 1998. Cad Saúde Pública 2004; 20:735-43.

10. Santos M. A natureza do espaço: técnica e tempo, razão e emoção. São Paulo: Editora Hucitec; 1996.

11. Castellanos PL. Epidemiologia, saúde pública, situação de saúde e condições de vida. Considerações conceituais. In: Barata $\mathrm{RB}$, organizadora. Condições de vida e situação de saúde. Rio de Janeiro: ABRASCO; 1997. p. 31-75. (Série Saúde e Movimento, 4).

12. Sinnecker H. General epidemiology. London: John Wiley \& Sons; 1976.

13. Rosicky B. Natural foci of diseases. In: Cockburn A, editor. Infectious diseases: their evolution and eradication. Springfield: Charles C. Thomas Publisher; 1967. p. 108-26.

14. Ostfeld RS, Glass GE, Keesing F. Spatial epidemiology: an emerging (or re-emerging) discipline. Trends Ecol Evol 2005; 20:328-36.

15. Correia VRM, Carvalho MS, Sabroza PC, Vasconcelos $\mathrm{CH}$. Remote sensing as a tool to survey endemic diseases in Brazil. Cad Saúde Pública 2004; 20:891-904. 
16. Bradley DJ. Regulation of parasite populations. Trans R Soc Trop Med Hig 1972; 66:697-708.

17. Kawa H, Sabroza PC. Espacialização da leishmaniose tegumentar na Cidade do Rio de Janeiro. Cad Saúde Pública 2002; 18:853-65.

18. Said RVA. A percepção popular da leishmaniose tegumentar americana: estudo sorológico realizado junto a famílias de baixa renda da localidade do Pau da Fome (Jacarepaguá, Rio de Janeiro) [Dissertação de Mestrado]. Rio de Janeiro: Escola Nacional de Saúde Pública, Fundação Oswaldo Cruz; 1984.

19. Lima LC. Ruralização da Lutzomyia intermedia: um provável caso de pré-adaptação. Rev Saúde Pública 1986; 20:102-4.

20. Toledo LM. Leishmaniose tegumentar e leishmaniose visceral em área periurbana no Município do Rio de Janeiro [Dissertação de Mestrado]. Rio de Janeiro: Instituto Oswaldo Cruz, Fundação Oswaldo Cruz; 1987.

21. Sabroza PC. Relatório de pesquisa da leishmaniose tegumentar no Rio de Janeiro. Rio de Janeiro: Escola Nacional de Saúde Pública, Fundação Oswaldo Cruz; 1983.

22. Kawa H. A produção do lugar de transmissão da leishmaniose tegumentar na Cidade do Rio de Janeiro [Tese de Doutorado]. Rio de Janeiro: Escola Nacional de Saúde Pública, Fundação Oswaldo Cruz; 2003.

23. Correia VRM, Monteiro AMV, Carvalho MS, Werneck GL. Uma aplicação do sensoriamento remoto para a investigação de endemias urbanas. Cad Saúde Pública 2007; 23:1015-28.

24. Camara G, Souza RCM, Freitas UM, Garrido J. SPRING: integrating remote sensing and GIS by object-oriented data modeling. Comput Graph 1996; 20:395-403.

25. Ponzoni FJ. Comportamento espectral da vegetação. In: Meneses PR, Madeira Netto JS, organizadores. Sensoriamento remoto - reflectância dos alvos naturais. Brasília: Editora UnB/Embrapa Cerrados; 2001. p. 157-95.
26. Dajoz R. Ecologia geral. Petrópolis: Editora Vozes/ São Paulo: Edusp; 1973.

27. Bailey TC, Gatrell AC. Interactive spatial data analysis. Essex: Longman Scientific \& Technical; 1995.

28. Lei Estadual no ${ }^{\circ} .2 .377$, de 28 de junho de 1974. Cria o Parque Estadual da Pedra Branca e dá outras providências. Diário Oficial do Estado do Rio de Janeiro 1974; 2 jul.

29. Secretaria Municipal de Planejamento e Coordenação Geral, Prefeitura da Cidade do Rio de Janeiro. Plano urbanístico básico da Cidade do Rio de Janeiro. Rio de Janeiro: Prefeitura da Cidade do Rio de Janeiro; 1997.

30. Magalhães RRSG. A leishmaniose tegumentar: estudo do primeiro foco decorrido na Cidade do Rio de Janeiro [Dissertação de Mestrado]. Rio de Janeiro: Escola Nacional de Saúde Pública, Fundação Oswaldo Cruz; 2001.

31. Gomes AC, Rabello EX, Santos JLF, Galati EAB. Aspectos ecológicos da leishmaniose tegumentar americana: 1. Estudo experimental da freqüência de flebotomíneos a ecótopos artificiais com referência especial a Psychodopygus intermedius. Rev Saúde Pública 1980; 14:540-56.

32. Bradley DJ. An exploration of chronotones: a concept for understanding the health processes of changing ecosystems. Ecohealth 2004; 1:165-71.

33. Lagrotta MTF, Silva WC, Souza-Santos R. Identification of key areas for Aedes aegypti control through geoprocessing in Nova Iguaçu, Rio de Janeiro State, Brazil. Cad Saúde Pública 2008; 24:70-80.

34. Barcellos C, Sabroza PC. The place behind the case: leptospirosis risks and associated environmental conditions in a flood-related outbreak in Rio de Janeiro. Cad Saúde Pública 2001; 17 Suppl:59-67.

Recebido em 03/Jun/2009

Versão final reapresentada em 19/Nov/2009

Aprovado em 03/Mar/2010 